Polymer Journal, Vol. 38, No. 10, pp. 1035-1042 (2006)

(C) 2006 The Society of Polymer Science, Japan

\title{
Helix-Sense-Selective Free Radical Polymerization of $N$-(Triphenylmethyl)methacrylamide Derivatives
}

\author{
A. K. M. Fakhrul Azam, ${ }^{1}$ Masami Kamigaito, ${ }^{1}$ and Yoshio OKAмото ${ }^{2, \dagger}$ \\ ${ }^{1}$ Department of Applied Chemistry, Graduate School of Engineering, Nagoya University, \\ Furo-cho, Chukusa-ku, Nagoya 464-8603, Japan \\ ${ }^{2}$ EcoTopia Science Institute, Nagoya University, Furo-cho, Chukusa-ku, Nagoya 464-8603, Japan
}

(Received June 1, 2006; Accepted July 12, 2006; Published August 30, 2006)

\begin{abstract}
Two novel monomers, $N$-[( \pm -(2-fluorophenyl)(4-fluorophenyl)(phenyl)methyl]methacrylamide (2F4FPhMAM) and $N$-[(4-butyl)triphenylmethyl]methacrylamide (BuTrMAM), were synthesized and polymerized in the presence of (+)- and (-)-menthol as the chiral additive at different temperatures. The obtained polymers, P2F4FPhMAM and PBuTrMAM, are optically active. P2F4FPhMAM is not soluble in common organic solvents and no enantiomer selection was observed in the polymerization of racemic 2F4FPhMAM in the presence of the optically active additive (+)- and (-)-menthols. PBuTrMAM is soluble in THF and chloroform. The circular dichroism spectra of the polymers is similar to that of optically active poly[(triphenylmethyl)methacrylamide] with a prevailing one-handed helicity, suggesting that the present polymers also have a prevailing one-handed helicity. The tacticity of the polymers was estimated from the ${ }^{1} \mathrm{H}$ NMR spectrum of polymethacrylamide derived in $\mathrm{D}_{2} \mathrm{SO}_{4}$. The polymers are almost $100 \%$ isotactic. The chiroptical properties of the obtained polymers were studied in detail. [doi:10.1295/polymj.PJ2006050]

KEY WORDS Asymmetric Polymerization / Optically Active Polymer / Helicity / Chiral Recognition / Isotacticity / HPLC / Stereospecific Polymerization /
\end{abstract}

Optically active polymers, especially helical polymers, play an important role in the field of polymer science as they have a wide variety of potential applications based on a chiral structure, such as chiral recognition toward racemic compounds and liquid crystal formation. ${ }^{1-8}$ Many stereoregular polymers are known to have a helical conformation in the solid state, which may be maintained even in solution if the side chain is very bulky. The optical activity of these polymers is mainly based on a single-handed helical conformation of the main chain which is maintained by steric repulsion between the bulky side groups. Recently, we found that Lewis acids such as rare earth metal triflates significantly increase the isotactic specificity during the radical polymerization of acrylamide and methacrylamide derivatives. ${ }^{9-12}$ The radical polymerization of the methacrylates with a bulky side group, such as triphenylmethyl methacrylate (TrMA) ${ }^{13}$ and 1-phenyldibenzosuberyl methacrylate (PDBSMA) ${ }^{14}$ proceeds in an isotactic-specific manner due to the steric repulsion among the bulky side groups. The helix-sense-selective polymerization of PDBSMA through free radical mechanism gives rise to an optically active, helical polymer having an excessive single-handed helicity from a achiral monomer. ${ }^{14}$ This insisted us to study bulky methacrylamides, $N$-(triphenylmethyl)-methacrylamide (TrMAM) and its deriva- tive, $N$-[(4,4'-dibutyl)triphenylmethyl]methacrylamide (DBuTrMAM). ${ }^{15}$ The polymers (PDBuTrMAM) prepared by the polymerization of DBuTrMAM in $(+)$ and (-)-menthol were optically active, and their optical rotation was opposite to that of menthol. This suggests that the optical rotation may not due to the incorporation of menthol residue in the polymer. The CD intensity of the PDBuTrMAM was lower than that of the anionically polymerized one-handed helical poly(TrMA) with a specific rotation of $[\alpha]_{\mathrm{D}}+350^{\circ}$, indicating that the one-handedness of the PDBuTrMAMs may not be high. In the present study, chiral 2F4FPhMAM was synthesized to observe the possibilities of the enantiomer selective polymerization of racemic monomer under chiral condition. To investigate the helix-sense-selective polymerization, BuTrMAM was copolymerized with a small amount of optically active 2F4FPhMAM. BuTrMAM was also polymerized using radical initiators under various conditions, particularly chiral conditions. The polymer (P2F4FPhMAM) prepared from 2F4FPhMAM was not soluble in common organic solvents but PBuTrMAM was soluble in chloroform and THF. The optically active PBuTrMAM exhibited a low chiral recognition. The chiroptical properties of these polymers were also studied in details. 


\section{EXPERIMENTAL}

\section{Materials}

All the reagents used for synthesis of monomers were bought from Aldrich, Kishida, and Kanto Kagaku, and were used without further purification. 2,2'-Azobis-isobutyronitrile (AIBN; Kishida; purity $>99 \%$ ) was purified by recrystallization from methanol. The chiral additives, (+)-neomenthol (TCI; $>96 \%$ ), $(R)-(-)-2$-octanol (TCI; >98\%), $(R)-(-)-2-$ heptanol (Aldrich; >98\%), $(S)$-3-hydroxytetrahydrofurane (TCI; $>98 \%$ ), and $(R)-(+)$-tetrahydrofuran-2carboxylic acid (TCI; $>98 \%$ ), were used after being distilled from $\mathrm{CaH}_{2}$ under a reduced pressure. Dry solvents, THF and toluene (Kanto Kagaku), and the chiral solvents (additives), (-)- and (+)-menthols (Kishida; >99\%), were used for polymerization without further purification.

\section{Monomer Synthesis \\ (土)-2F4FPhMAM}

This monomer was synthesized by three steps reaction. Firstly, synthesis of the corresponding alcohol, then the amination of the alcohol, and finally, synthesis of the monomer from the obtained amine.

Synthesis of Alcohol. Phenyl magnesium bromide in diethyl ether was prepared by a conventional method from bromobenzene $(43.6 \mathrm{~mL}, 0.41 \mathrm{~mol})$ and $\mathrm{Mg}$ turnings $(10.2 \mathrm{~g}, 0.42 \mathrm{~mol})$. A solution of $2,4^{\prime}$-difluorobenzophenone $(65 \mathrm{~g}, 0.298 \mathrm{~mol})$ in dry ether $(200 \mathrm{~mL})$ was added dropwise to the Grignard reagent, and the reaction was continued for $6 \mathrm{~h}$ at room temperature. Then, $400 \mathrm{~mL}$ of $3 \mathrm{~N}$ aq. $\mathrm{HCl}$ was slowly added to the reaction mixture. The aq. solution was neutralized by $4 \mathrm{~N}$ aq. $\mathrm{NaOH}$ and aq. $\mathrm{NH}_{4} \mathrm{Cl}$. The product was extracted with ether and dried over $\mathrm{MgSO}_{4}$. After the evaporation of the solvent, the obtained alcohol was recrystallized twice from hexane. Yield: $74.4 \mathrm{~g}$ (84\%), mp 59-60 ${ }^{\circ} \mathrm{C}$.

Synthesis of Amine from Alcohol. Phosphorus tribromide $(5.12 \mathrm{~mL}, 0.028 \mathrm{~mol})$ was added dropwise to the alcohol $(25 \mathrm{~g}, 0.084 \mathrm{~mol})$ dissolved in diethyl ether $(150 \mathrm{~mL})$ at $0{ }^{\circ} \mathrm{C}$. The reaction was continued for $4 \mathrm{~h}$ and the solution in a flask turned to brownish color. Then, liquid ammonia was added to the reaction mixture at $-78^{\circ} \mathrm{C} .{ }^{16}$ The organic phase was separated, dried $\left(\mathrm{MgSO}_{4}\right)$, and evaporated under a reduced pressure. The obtained compound was recrystallized in hexane. Yield: $21.5 \mathrm{~g}(86.4 \%), \mathrm{mp} 51-52^{\circ} \mathrm{C}$.

Synthesis of ( \pm )-2F4FPhMAM from the Amine. Triethylamine $(12.3 \mathrm{~mL}, 0.088 \mathrm{~mol})$ was added to a chloroform solution of the amine $(13 \mathrm{~g}, 0.044 \mathrm{~mol})$ in a flask. The solution was cooled in an ice water bath and methacryloyl chloride $(5 \mathrm{~mL}, 0.048 \mathrm{~mol}$ ) was add- ed dropwise to the flask. The reaction was continued for $2 \mathrm{~h}$ at $0^{\circ} \mathrm{C}$ and then for $24 \mathrm{~h}$ at room temperature, and finally the mixture was refluxed for $1 \mathrm{~h}$. The reaction mixture was washed with saturated aq. $\mathrm{NaHCO}_{3}$ $(200 \mathrm{~mL})$ three times and two times with distilled water. The organic phase was separated and dried with $\mathrm{MgSO}_{4}$. After the evaporation of the solvent, the product was recrystallized with hexane and chloroform. Yield: $13.5 \mathrm{~g}(76 \%), \mathrm{mp} 95^{\circ} \mathrm{C}$.

${ }^{1} \mathrm{H} \mathrm{NMR}\left(\mathrm{CDCl}_{3}\right): \delta 1.97$ (s, 3H, allyl $\left.\mathrm{CH}_{3}\right), 5.36$ (s, 1H, vinyl), $5.72(\mathrm{~s}, 1 \mathrm{H}$, vinyl), $6.95(\mathrm{~s}, 1 \mathrm{H},-\mathrm{NH})$, 7.01-7.29 (m, 13H, aromatic) ppm. Elemental analysis. Found: C, 76.01\%; H, 5.27\%; N, 3.74\%. Calculated for $\mathrm{C}_{23} \mathrm{H}_{19} \mathrm{~F}_{2} \mathrm{NO}$ : C, 76.02\%; H, 5.27\%; N, 3.85\%.

\section{BUTrMAM}

(4-Butyltriphenyl)methanol was synthesized by the Grignard reaction of benzophenone with 4-butylphenylmagnesium bromide in ether. The obtained liquid alcohol was purified by column chromatography $(20 \mathrm{~g}, 75 \%)$. From this alcohol, (4-butyltriphenylmethyl)amine was synthesized with liquid ammonia. ${ }^{16}$ The obtained liquid amine was purified by column chromatography $(7.3 \mathrm{~g}, 49 \%)$. Finally BuTrMAM was synthesized by the reaction of (4-butyltriphenylmethyl)amine and methacryloyl chloride in the presence of triethylamine in chloroform in the same way as the synthesis of 2F4FPhMAM. Yield: $8.5 \mathrm{~g}$, (95\%).

${ }^{1} \mathrm{H} \mathrm{NMR}\left(\mathrm{CDCl}_{3}\right): \delta 0.92\left(\mathrm{~m}, 3 \mathrm{H}, n\right.$-butyl $\left.\mathrm{CH}_{3}\right)$, $1.36\left(\mathrm{~m}, 2 \mathrm{H}, n\right.$-butyl $\left.\mathrm{CH}_{2}\right), 1.56\left(\mathrm{~m}, 2 \mathrm{H}, n\right.$-butyl $\left.\mathrm{CH}_{2}\right)$, $1.97\left(\mathrm{~s}, 3 \mathrm{H}\right.$, allyl $\left.\mathrm{CH}_{3}\right), 2.58\left(\mathrm{t}, 2 \mathrm{H}, n\right.$-butyl $\left.\mathrm{CH}_{2}\right), 5.34$ (s, $1 \mathrm{H}$, vinyl), $5.7(\mathrm{~s}, 1 \mathrm{H}$, vinyl), $6.96(\mathrm{~s}, 1 \mathrm{H},-\mathrm{NH})$, 7.09-7.31 (m, 14H, aromatic) ppm. Elemental analysis. Found: C, $84.53 \%$; H, 7.45\%; N, 3.66\%. Calculated for $\mathrm{C}_{27} \mathrm{H}_{29} \mathrm{NO}$ : C, $84.55 \%$; $\mathrm{H}, 7.62 \%$; N, $3.65 \%$.

\section{Polymerization}

The radical polymerization was carried out under dry nitrogen in a glass tube equipped with a threeway stopcock using AIBN as an initiator at $60^{\circ} \mathrm{C}$. The polymerization using AIBN at $-20 \sim 40^{\circ} \mathrm{C}$ was initiated by the irradiation of UV light $(400 \mathrm{~W}$ high-pressure mercury lamp). Liquid materials were transferred to the glass tube using syringes and the solid monomer using a funnel having a nitrogen gas inlet tube. As BuTrMAM is very reactive, it was preserved as a hexane solution. The BuTrMAM solution was placed in the glass tube and then hexane was evaporated under a reduced pressure at low temperature $\left(0^{\circ} \mathrm{C}\right)$ and a solvent of polymerization was added in it. The solution was maintained at the prescribed temperature for $24 \mathrm{~h}$. The polymerization was terminated by cooling the reaction mixture at $-78^{\circ} \mathrm{C}$. The reaction mixture was dissolved in chloroform $(5 \mathrm{~mL})$, and the solution was poured into a large 
amount of methanol. The precipitated polymers were isolated using a centrifuge, washed several times with methanol to remove the unreacted monomer and the chiral additives, and dried at $60^{\circ} \mathrm{C}$ for $10 \mathrm{~h}$. The absence of menthol in the obtained polymers was confirmed by measuring the IR spectra in the solid state and the ${ }^{1} \mathrm{H}$ NMR of the polymer in $\mathrm{D}_{2} \mathrm{SO}_{4}$.

\section{Measurements in a Solid State}

The insoluble polymers were dispersed in liquid paraffin by grinding in a mortar, and imposed between quartz plates. ${ }^{15}$ The polymer concentrations and the UV intensities of the samples were almost the same for all cases.

\section{Solvolysis of BuTrMAM}

The solvolysis reaction of BuTrMAM was carried out in a mixture of $\mathrm{CD}_{3} \mathrm{OD} / \mathrm{CDCl}_{3}(1 / 1, \mathrm{v} / \mathrm{v})$ at $35^{\circ} \mathrm{C}$ in an NMR tube (Wilmad 507-PP). ${ }^{17}$ BuTrMAM $(0.15 \mathrm{~g}, 0.4 \mathrm{mmol})$ was dissolved in the solvent $(1 \mathrm{~mL})$, the tube was placed in a water bath at $35^{\circ} \mathrm{C}$, and reaction was monitored by ${ }^{1} \mathrm{H}$ NMR spectroscopy at $35^{\circ} \mathrm{C}$.

\section{Measurements}

The ${ }^{1} \mathrm{H}$ NMR spectra were recorded on a Varian Gemini 2000 spectrometer $\left(400 \mathrm{MHz}\right.$ for $\left.{ }^{1} \mathrm{H}\right)$. The number average molecular weight $\left(M_{\mathrm{n}}\right)$ and polydispersity $\left(M_{\mathrm{w}} / M_{\mathrm{n}}\right)$ of the obtained polymers were determined by size-exclusion chromatography (SEC) calibrated using standard polystyrenes on a JASCO PU-980 pump equipped with a JASCO RI-930 detector using TSKgel $\mathrm{GMH}_{\mathrm{HR}}-\mathrm{H}$ and $\mathrm{G} 3000_{\mathrm{HR}}$ columns connected in series (eluent THF; temperature $40^{\circ} \mathrm{C}$ ). The optical rotation was measured in either THF or chloroform at room temperature with a JASCO P1030 polarimeter. The circular dichroism (CD) spectra were measured with a JASCO J-720L spectrometer.

\section{Resolution of 2F4FPhMAM}

The resolution of racemic 2F4FPhMAM was examined using several commercially available chiral HPLC columns, such as CHIRALCEL OD, CHIRALPAK AD, CHIRALCEL OJ, and many other home-made polysaccaride-based chiral columns. Enantiomers were partially resolved (enantiomeric excess $80 \%$ ), but enantiomeric pure isomers were not obtained.

\section{RESULTS AND DISCUSSION}

\section{Radical Polymerization of 2F4FPhMAM}

Some methacrylates having bulky side groups afford the prevailing one-handed helical polymers by anionic polymerization using optically active initiators, and even by the radical process in the presence
Table I. Radical polymerization of 2F4FPhMAM ${ }^{\mathrm{a}}$

\begin{tabular}{cclcc}
\hline Run & $\begin{array}{c}\text { Temp. } \\
\left({ }^{\circ} \mathrm{C}\right)\end{array}$ & Initiator & $\begin{array}{c}\text { Solvent } \\
(\mathrm{v} / \mathrm{v})\end{array}$ & $\begin{array}{c}\text { Yield }^{\mathrm{b}} \\
(\%)\end{array}$ \\
\hline 1 & 60 & AIBN & THF & 92 \\
2 & 60 & AIBN & Toluene & 90 \\
3 & 60 & AIBN & Toluene $/(+)$ Menthol $(5 / 2)$ & 99 \\
4 & 60 & AIBN & Toluene $/(-)$ Menthol $(5 / 2)$ & 99 \\
5 & 0 & AIBN/UV & Toluene $/(+)$ Menthol $(5 / 2)$ & 75 \\
6 & 0 & AIBN/UV & Toluene $/(-)$ Menthol $(5 / 2)$ & 70 \\
\hline
\end{tabular}

${ }^{\mathrm{a}}$ Initiator $=\operatorname{AIBN}(0.02 \mathrm{M})$, time $=24 \mathrm{~h},[\mathrm{M}]_{0}=0.5 \mathrm{~mol} / \mathrm{L}$. ${ }^{\mathrm{b}}$ Methanol-insoluble part.

of optically active additives such as menthol and menthanthiol. ${ }^{14}$ The formation of the prevailing one-handed helical polymers by the radical process has been ascribed to the fact that the chain transfer rates of the growing radicals with a right- or left-handed helicity to an optically active transfer agent can be different, and the helical growing polymer with a large transfer constant has a lower chance to propagate to the high molecular weight polymer compared with the opposite helical polymer with a lower transfer constant. Although the radical polymerization of $2 \mathrm{~F} 4 \mathrm{FPhMAM}$ afforded the polymer in good yields (Table I), the anionic polymerization of this monomer using $n$-BuLi in toluene at $-78^{\circ} \mathrm{C}$ did not proceed and no polymer was obtained. Usually, acrylamides and methacrylamides with an amide proton cannot be polymerized by the typical anionic process with alkyl lithiums and Grignard reagents. ${ }^{18}$

The radically obtained polymers were insoluble in organic solvents as well as poly(TrMAM). ${ }^{15}$ These polymers were dissolved in strong acids, such as concentrated sulfuric acid, accompanying with the cleavage of the bulky side derivative of trityl group to produce polymethacrylamide. The tacticity of the obtained polymers was directly determined from the ${ }^{1} \mathrm{H}$ NMR spectra of the polymethacrylamide derived from the original polymers in $\mathrm{D}_{2} \mathrm{SO}_{4}{ }^{15,19}$ The ${ }^{1} \mathrm{H}$ NMR spectra indicated that the obtained polymers were nearly $100 \%$ isotactic similar to poly(TrMAM). ${ }^{15}$ The polymer may be an equimolar mixture of left- and right-handed helices.

Optically active polymers were obtained in the polymerization of racemic $2 \mathrm{~F} 4 \mathrm{FPhMAM}$ in presence of chiral additive (+)- and (-)-menthol but no enantiomer selection was observed in this process. As P2F4FPhMAMs were insoluble in organic solvents, the CD spectra of these polymers could not be measured in solution, but the spectra were obtained for the polymer particles dispersed in liquid paraffin (Nujol) (Figure 1). ${ }^{20}$ The spectral pattern was similar to that of PTrMAM obtained in menthol, ${ }^{15}$ and the CD intensity was higher for the polymers prepared at $0{ }^{\circ} \mathrm{C}$. 


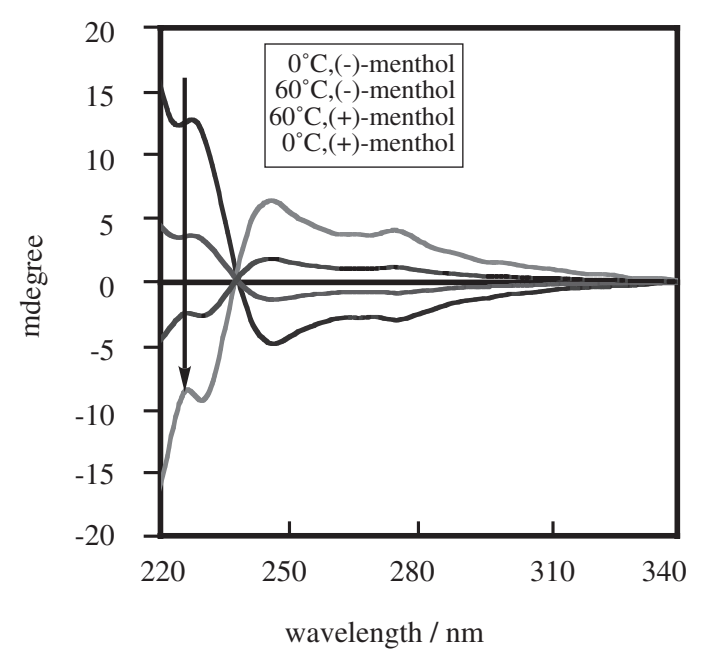

Figure 1. CD spectra of P2F4FPhMAM in paraffin (run 3 to 6 in Table I) at r.t.

These results support the formation of the prevailing one-handed helical P2F4FPhMAM in menthol.

When BuTrMAM was copolymerized with a small amount of optically active 2F4FPhMAM, the obtained copolymer showed the chiroptical properties, which are expected only from the contribution of 2F4FPhMAM, suggesting that no helix-senseselective polymerization proceeded.

2F4FPhMAM was not solvolyzed at all in methanol/chloroform $(1 / 1, \mathrm{v} / \mathrm{v})$ at $35^{\circ} \mathrm{C}$ even after $10 \mathrm{~d}$, whereas the half-life of TrMA under the same conditions is only $15 \mathrm{~min} .{ }^{21}$ This indicates that 2F4FPhMAM is much stronger towards hydrolysis and the obtained polymer must be more stable compared with poly(TrMA) when used as a chiral stationary phase in HPLC with polar alcoholic solvents.

\section{Radical Polymerization of BuTrMAM}

The radical polymerization of BuTrMAM was carried out in toluene and THF. Although PTrMAM is insoluble in common organic solvents, PBuTrMAM

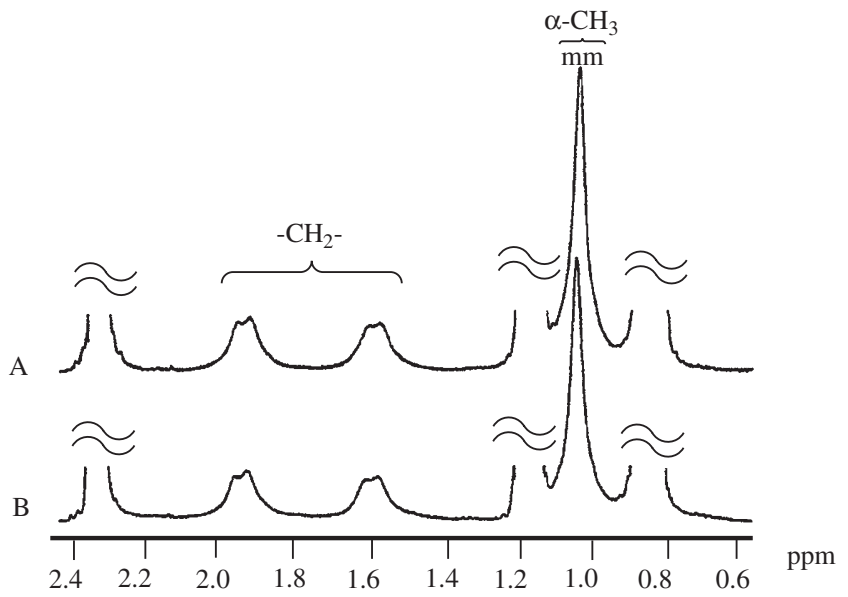

Figure 2. $400 \mathrm{MHz}{ }^{1} \mathrm{H}$ NMR spectra of PMAM (A, derived from PBuTrMAM (run 1 in Table II); B, derived from PBuTrMAM (run 2 in Table II)) (at $60^{\circ} \mathrm{C}$ in $\mathrm{D}_{2} \mathrm{SO}_{4}$ ). The peaks $(0.85,1.2,2.35 \mathrm{ppm})$ are due to the butyl protons on the triphenylmethyl residue of the by-product during sulphuric acid-induced decomposition.

is soluble in chloroform and THF because of the $n$-butyl group in one of the phenyl group of bulky trityl side chain. The tacticity of the obtained polymer was estimated by the same method as that for P2F4FPhMAM. ${ }^{15,19}$ When the PBuTrMAMs (run 1 and 2 in Table II) were dissolved in $\mathrm{D}_{2} \mathrm{SO}_{4}$, the ${ }^{1} \mathrm{H}$ NMR in Figure 2 shows only one methyl peak due to the isotactic $(\mathrm{mm})$ sequence at $1.05 \mathrm{ppm}$ and two sets of doublet due to the methylene group at 1.60 and $1.95 \mathrm{ppm}$, indicating that the PBuTrMAMs are highly isotactic. The two ${ }^{1} \mathrm{H}$ NMR spectra are almost identical to each other, which indicates almost no solvent effect on the polymer tacticity.

The polymerization in an optically active medium may helix-sense-selectively proceed because the propagation rates of right- and left-handed helical polymer radicals might be different due to the existence of a chiral substance. The chain transfer to the chiral medi-

Table II. Radical polymerization of BuTrMAM ${ }^{\mathrm{a}}$

\begin{tabular}{|c|c|c|c|c|c|c|c|}
\hline Run & $\begin{array}{c}\text { Temp. } \\
\left({ }^{\circ} \mathrm{C}\right)\end{array}$ & Solvent & $\begin{array}{c}\text { Yield }^{\mathrm{b}} \\
(\%)\end{array}$ & $\begin{array}{c}M_{\mathrm{n}}^{\mathrm{c}} \\
\times 10^{-4}\end{array}$ & $M_{\mathrm{w}} / M_{\mathrm{n}}^{\mathrm{c}}$ & $\begin{array}{l}{[\alpha]_{D}{ }^{d}} \\
(\mathrm{deg})\end{array}$ & $\begin{array}{r}{[\alpha]_{365}{ }^{\mathrm{d}}} \\
(\mathrm{deg})\end{array}$ \\
\hline 1 & 60 & Toluene & 65 & 2.6 & 5.2 & - & - \\
\hline 2 & 60 & THF & 71 & 1.5 & 2.1 & - & - \\
\hline 3 & $-20 / \mathrm{UV}$ & (+)-Menthol & 30 & 6.1 & 6.2 & -9.4 & -28.2 \\
\hline 4 & $-20 / \mathrm{UV}$ & (-)-Menthol & 27 & 9.6 & 5.4 & 9.5 & 28.9 \\
\hline 5 & $0 / \mathrm{UV}$ & (+)-Menthol & 81 & 30.0 & 5.3 & -9.7 & -29.3 \\
\hline 6 & $0 / \mathrm{UV}$ & (-)-Menthol & 79 & 29.4 & 5.3 & 9.8 & 29.4 \\
\hline 7 & 20/UV & $(+)$-Menthol & 88 & 6.4 & 9.7 & -7.0 & -21.7 \\
\hline 8 & $20 / \mathrm{UV}$ & (-)-Menthol & 91 & 8.2 & 9.8 & 6.8 & 21.8 \\
\hline 9 & 60 & $(+)$-Menthol & 90 & 5.2 & 3.6 & -3.1 & -8.8 \\
\hline 10 & 60 & (-)-Menthol & 84 & 4.2 & 3.0 & 2.9 & 8.6 \\
\hline
\end{tabular}


um may also be responsible for the helix-sense-selection as described before. Table II shows the results of the radical polymerization of BuTrMAM in $(+)-$ and $(-)$-menthols. The PBuTrMAMs prepared in (+)and (-)-menthol were optically active, and their optical rotation was opposite to that of menthol. This suggests that the optical rotation may be not due to the incorporation of the menthol residue in the polymer. The polymerization at $0{ }^{\circ} \mathrm{C}$ produced the polymers having a larger specific rotation than that at $20^{\circ} \mathrm{C}$. The optical activity gradually decreased with an increase of the polymerization temperature.

The spectral pattern of PBuTrMAMs is similar to that of the PDBuTrMAM obtained in the same menthol (Figure 3) ${ }^{15}$ The CD intensity of the polymer also decreased with an increase in the polymerization temperature. These results support the formation of the prevailing one-handed helical PBuTrMAM in menthol. In Figure 3, split-type CD peaks were observed at 205, 215, 225 and $245 \mathrm{~nm}$, and their pattern is different from that of the highly one-handed helical poly(TrMA) that has the CD peaks at 208 and $232 \mathrm{~nm} .{ }^{22}$ Furthermore, the CD patterns of poly(TrMA) 22 and poly(1-phenyldibenzosuberyl methacrylate $)^{14}$ are similar to each other but those are different

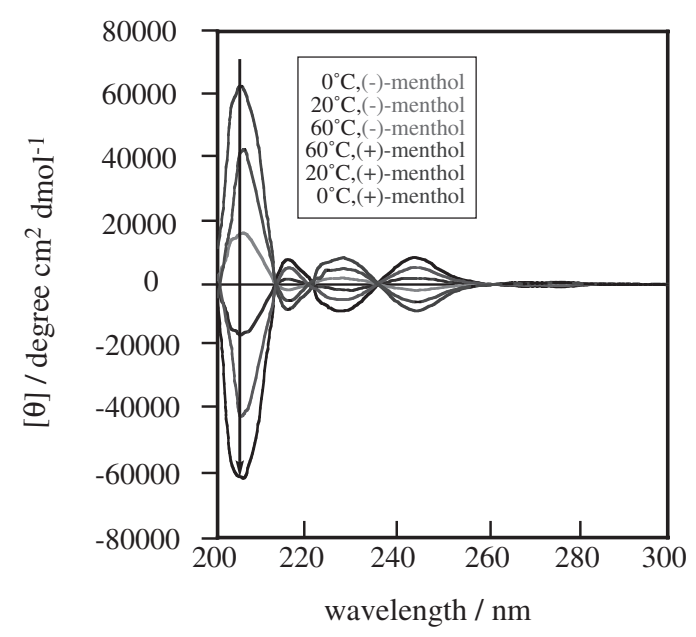

Figure 3. CD spectra of the PBuTrMAMs in THF (Table II) at r.t. from the $\operatorname{poly}(N$-triphenylmethylmethacrylamide $) .{ }^{15}$ Moreover, the crystal structure of TrMA ${ }^{23}$ is different from that of TrMAM. ${ }^{24}$ Thus, we believe that the propeller structures of the trityl groups in the bulky polymethacrylates are likely different from that of the bulky polymethacrylamides. The $\mathrm{CD}$ intensity around $205 \mathrm{~nm}$ and optical rotation of the helical PBuTrMAMs were lower than those of the one-handed helical poly(TrMA)s. This indicates that the onehandedness of the PBuTrMAMs may not be high, and the propeller structure of the trityl group in PBuTrMAM may not effectively contribute to the optical activity and CD intensity.

The molecular weights of the polymers obtained in menthols were higher than that prepared in THF (Table II), probably because of the lower chain transfer constant of menthols. The molecular weight of the polymer obtained at $0^{\circ} \mathrm{C}$ was higher than that of $60^{\circ} \mathrm{C}$. The chain transfer may more frequently occur at $60^{\circ} \mathrm{C}$. The polymer yield became very low at $-20^{\circ} \mathrm{C}$. Menthol was easily solidified at this temperature and the polymerization system become heterogeneous.

The polymerization of BuTrMAM was also carried out using different amounts of $(+)$-menthol in hexane (Table III). The polymer exhibited the highest CD intensity when the solvent was pure (+)-menthol (Figure 4). The CD intensities of these polymers were proportional to their optical rotation (Figure 5), and the optical activity decreased with a decrease of $(+)$ menthol concentration in the polymerization system.

\section{Radical Polymerization of BuTrMAM in the Presence of Optically Active Additives}

Other chiral alcohols and acid, such as $(+)$-neomenthol (1), $(R)-(-)$-2-octanol (2), $(R)-(-)$-2-heptanol (3), $(S)$-3-hydroxytetrahydrofurane $(4)$, and $(R)-(+)$-tetrahydrofuran-2-carboxylic acid (5) (Scheme 2), were also used as the optically active additives or solvents for the polymerization of BuTrMAM to enhance the optical activity or the one-handedness of the PBuTrMAM (Table IV). However, compared with menthol, these compounds did not enhance the optical

Table III. Radical polymerization of BuTrMAM in a different concentration of (+)-menthol in hexane ${ }^{\mathrm{a}}$

\begin{tabular}{cccccccc}
\hline Run & $\begin{array}{c}\text { Temp. } \\
\left({ }^{\circ} \mathrm{C}\right)\end{array}$ & $\begin{array}{c}\text { Menthol/Hexane } \\
(\mathrm{v} / \mathrm{v})\end{array}$ & $\begin{array}{c}\text { Yield }^{\mathrm{b}} \\
(\%)\end{array}$ & $\begin{array}{c}M_{\mathrm{n}}{ }^{\mathrm{c}} \\
\times 10^{-4}\end{array}$ & $M_{\mathrm{w}} / M_{\mathrm{n}}{ }^{\mathrm{c}}$ & $\begin{array}{c}{[\alpha]_{\mathrm{D}}{ }^{\mathrm{d}}} \\
(\mathrm{deg})\end{array}$ & $\begin{array}{c}{[\alpha]_{365}{ }^{\mathrm{d}}} \\
(\mathrm{deg})\end{array}$ \\
\hline 1 & $0 / \mathrm{UV}$ & $1 / 0$ & 81 & 30.0 & 5.3 & -9.7 & -29.3 \\
2 & $0 / \mathrm{UV}$ & $2 / 1$ & 72 & 3.65 & 3.5 & -7.4 & -22.3 \\
3 & $0 / \mathrm{UV}$ & $1 / 1$ & 67 & 4.88 & 3.6 & -7.3 & -22.1 \\
4 & $0 / \mathrm{UV}$ & $1 / 2$ & 65 & 6.20 & 4.7 & -7.1 & -21.3 \\
5 & $0 / \mathrm{UV}$ & $1 / 3$ & 65 & 4.13 & 4.6 & -6.9 & -20.8 \\
\hline
\end{tabular}

${ }^{\mathrm{a}}$ Initiator $=\mathrm{AIBN}(0.02 \mathrm{M})$, time $=24 \mathrm{~h},[\mathrm{M}]_{0}=0.5 \mathrm{~mol} / \mathrm{L} .{ }^{\mathrm{b}}$ Methanol-insoluble part. ${ }^{\mathrm{c}}$ Determined by SEC in THF (PMMA standard) at $40{ }^{\circ} \mathrm{C}$. ${ }^{\mathrm{d}} \mathrm{In}^{\mathrm{CHCl}} \mathrm{CH}_{3}$ at r.t. 


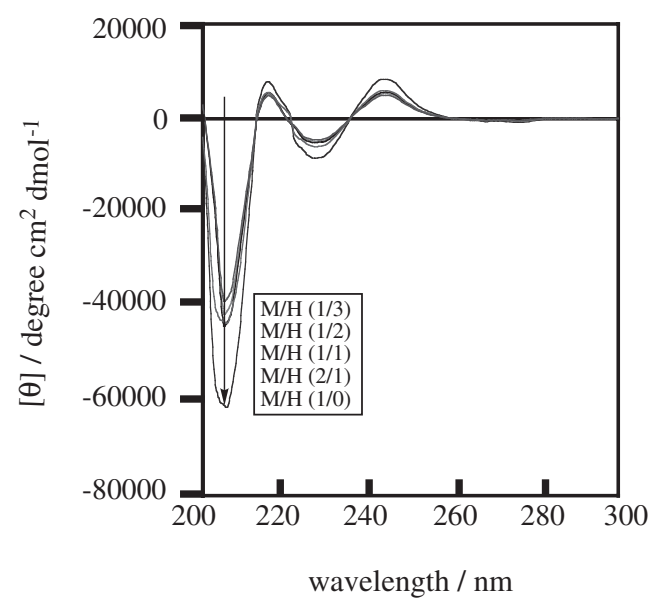

Figure 4. $\mathrm{CD}$ spectra of the PBuTrMAMs (polymerized in presence of different amount of (+)-menthol in hexane) in THF (Table III) at r.t.

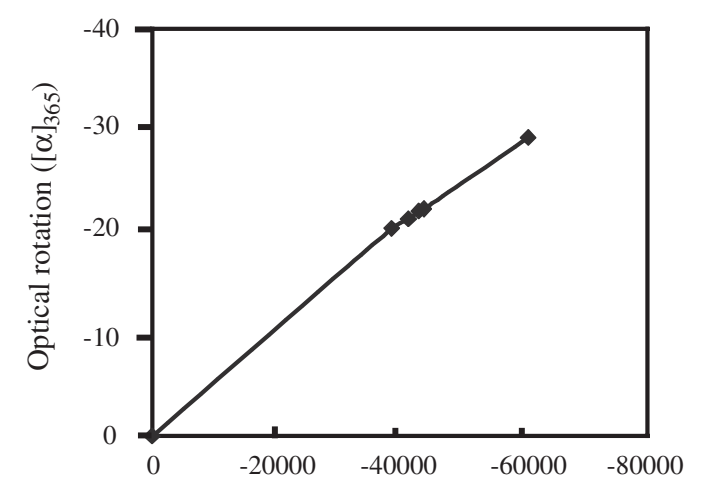

$[\theta] /$ degree $\mathrm{cm}^{2} \mathrm{dmol}^{-1}$

Figure 5. Plot of CD intensity at $205 \mathrm{~nm}$ (Figure 4) $v s$ optical rotation of the PBuTrMAMs (polymerized in presence of different amount of (+)-menthol in hexane) (Table III).

activity and probably one-handedness of the polymers. When pure (+)-neomenthol (1) was used as the solvent (run 6, Table IV), the optical activity of the obtained polymer was higher than that of the polymer obtained in $(+)$-neomenthol/hexane $(1 / 1, \mathrm{v} / \mathrm{v})$ (run 1, Table IV). But the effect is reverse when $(R)$ (-)-2-octanol (2) was used as a solvent (run 2 and 7,
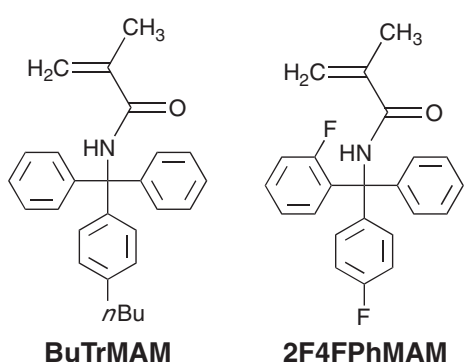<smiles>CC(C)C1CC[C@@H](C)CC1O</smiles><smiles>CC1CCC(C(C)C)C(O)C1</smiles>

2F4FPhMAM

(+)-Menthol (-)-Menthol
Scheme 1.<smiles>CC1CCC(C(C)C)C(O)C1</smiles>

1<smiles>CC(O)c1ccccc1</smiles>

2<smiles>CCCCCC(C)O</smiles>

3<smiles>O=C(O)[C]1CCCO1</smiles>

Scheme 2.

Table IV). In this case the optical activity decreased when the concentration of $(R)-(-)$-2-octanol increased in the polymerization solvent. The CD pattern of these polymers resembles with the polymers polymerized in presence of (+)- and (-)-menthol (Figure 6), which supports the formation of one-handed helical PBuTrMAM. The CD intensities of these polymers are low, which is probably due to the lower one-handedness of the polymers.

Chiral cobalt complexes have been successfully used for the asymmetric radical polymerization of TrMA derivatives. The radical polymerization of PDBSMA in the presence of $N, N^{\prime}$-bis(3,5-di-tertbutylsalicylidene)-(1R,2R)-1,2-cyclohexanediaminatocobalt(II) (6) and $N, N^{\prime}$-bis $\{2-(2,4,6$-tri-methylbenzoyl)-3-oxobutylidene \}-(1S,2S)-1,2-diphenylethylenediaminatocobalt(II) (7) effectively induces a singlehanded helicity. ${ }^{25}$ These Co complexes were also used as chiral additives for the polymerization of

Table IV. Radical polymerization of BuTrMAM in a mixture of chiral additive and hexane ${ }^{\mathrm{a}}$

\begin{tabular}{|c|c|c|c|c|c|c|c|}
\hline Run & $\begin{array}{l}\text { Temp. } \\
\left({ }^{\circ} \mathrm{C}\right)\end{array}$ & $\begin{array}{c}\text { Chiral additive/Hexane } \\
(\mathrm{v} / \mathrm{v})\end{array}$ & $\begin{array}{l}\text { Yield }^{\mathrm{b}} \\
(\%)\end{array}$ & $\begin{array}{c}M_{\mathrm{n}}^{\mathrm{c}} \\
\times 10^{-4}\end{array}$ & $M_{\mathrm{w}} / M_{\mathrm{n}}{ }^{\mathrm{c}}$ & $\begin{array}{l}{[\alpha]_{D}{ }^{d}} \\
(\operatorname{deg})\end{array}$ & $\begin{array}{r}{[\alpha]_{365}{ }^{\mathrm{d}}} \\
(\mathrm{deg})\end{array}$ \\
\hline 1 & $0 / \mathrm{UV}$ & $\mathbf{1}(1 / 1)$ & 79 & 6.3 & 5.84 & -2.76 & -9.09 \\
\hline 2 & 0/UV & $2(1 / 1)$ & 91 & 9.1 & 4.58 & 1.8 & 5.4 \\
\hline 3 & 0/UV & $3(1 / 1)$ & 89 & 6.7 & 4.50 & 1.1 & 3.31 \\
\hline 4 & 0/UV & $4(1 / 1)$ & 90 & 11.8 & 4.68 & - & - \\
\hline 5 & 0/UV & $\mathbf{5}(1 / 1)$ & 69 & 1.3 & 3.04 & 0.8 & 2.1 \\
\hline 6 & $0 / \mathrm{UV}$ & 1 only & 76 & 24.7 & 4.45 & -5.8 & -16.8 \\
\hline 7 & 0/UV & 2 only & 89 & 17.9 & 4.33 & 1.01 & 3.1 \\
\hline
\end{tabular}

${ }^{\mathrm{a}}$ Initiator $=\mathrm{AIBN}(0.02 \mathrm{M})$, time $=24 \mathrm{~h},[\mathrm{M}]_{0}=0.5 \mathrm{~mol} / \mathrm{L} .{ }^{\mathrm{b}}$ Methanol-insoluble part. ${ }^{\mathrm{c}}$ Determined by SEC in THF (PMMA standard) at $40{ }^{\circ} \mathrm{C}$. ${ }^{\mathrm{d}} \mathrm{In} \mathrm{CHCl}_{3}$ at r.t. 


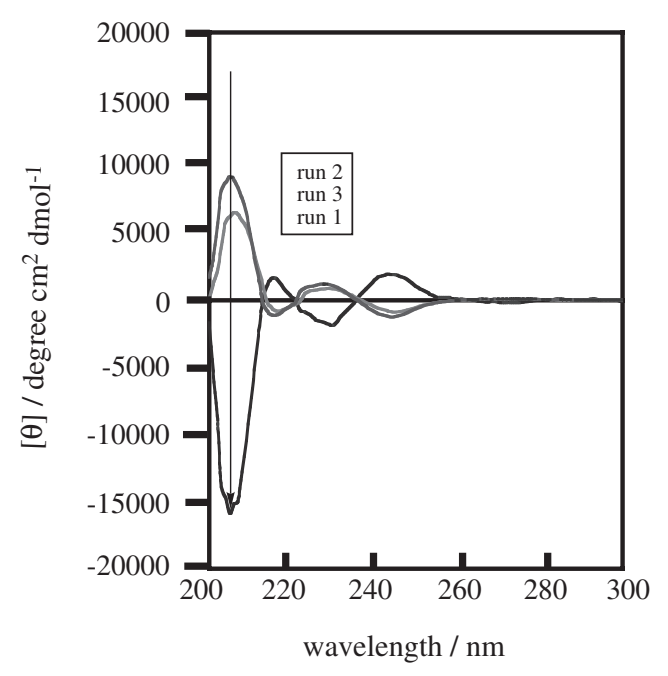

Figure 6. CD spectra of the PBuTrMAMs (polymerized in presence of different chiral additives) in THF (Table IV) at r.t.

BuTrMAM (Table V). However, the complexes functioned as the polymerization inhibitors. The optically inactive polymer was obtained in low yields only using complex $\mathbf{6}$.

\section{Properties of PBUTrMAMs}

BuTrMAM gave highly isotactic polymers by the radical polymerization. The isotactic specificity is ascribed to the helical structure of the growing chain. ${ }^{26}$ PBuTrMAMs have a stable helical structure. No change in $\mathrm{CD}$ after heating the polymer solution at $60^{\circ} \mathrm{C}$ for $10 \mathrm{~h}$. The $\mathrm{CD}$ intensity and the pattern were also not changed while measured in different temperatures. When the polymer maintains a stable helical structure, the polymer may be separated into $(+)$ - and (-)-fractions with opposite helicity. This was examined by the HPLC using several chiral sta- tionary phases, but no separation has so far attained.

The optically active PBuTrMAMs obtained with $(+)$ - and (-)-menthol at $0{ }^{\circ} \mathrm{C}$ were coated on silica gel to be used as chiral packing materials in an HPLC column $(25 \mathrm{~cm} \times 0.2 \mathrm{~cm}$ (i.d.)). The chiral recognition ability of the optically active PBuTrMAM was very low. The low chiral recognition ability of PBuTrMAM might be due to the lack of the propeller structure as mentioned above and also the low onehandedness of the polymers. As mentioned before, the propeller structure of the PBuTrMAM may not clearly exist in the polymer. Since the propeller structure is chiral, the absence of this structure may result in a decrease in the chiral recognition ability of the helical chain.

The one-handed helical poly(TrMA) exhibits a high chiral recognition ability for many racemates, ${ }^{27}$ but the polymer was easily solvolysed by the alcohols and acids used as the mobile phase in HPLC. ${ }^{21}$ On the other hand, BuTrMAM was very stable against the solvolysis under the same conditions, and therefore, the polymer would be very valuable as a chiral stationary phase for HPLC column, if it could show a high chiral recognition.

\section{CONCLUSIONS}

The helix-sense-selective radical polymerization of $N$-(triphenylmethayl)-methacrylamide derivatives, 2F4FPhMAM and BuTrMAM, were carried out. All the polymers were nearly $100 \%$ isotactic. The free radical polymerization of 2F4FPhMAM and BuTrMAM using chiral additives gave the polymers with the optical activity and CD adsorption based on an excess right- or left-handed helical conformation. The CD intensity and the optical rotation of PBuTrMAM

Table V. Radical polymerization of BuTrMAM in the presence of optically active cobalt complex ${ }^{\text {a }}$

\begin{tabular}{ccccccccc}
\hline Run & $\begin{array}{c}\text { Temp. } \\
\left({ }^{\circ} \mathrm{C}\right)\end{array}$ & $\begin{array}{c}\text { Solvent } \\
(\mathrm{v} / \mathrm{v})^{\mathrm{e}}\end{array}$ & $\begin{array}{c}\text { Cobalt complex } \\
(\text { conc./M) }\end{array}$ & $\begin{array}{c}\text { Yield }^{\mathrm{b}} \\
(\%)\end{array}$ & $\begin{array}{c}M_{\mathrm{n}}{ }^{\mathrm{c}} \\
\times 10^{3}\end{array}$ & $M_{\mathrm{w}} M_{\mathrm{n}}{ }^{\mathrm{c}}$ & $\begin{array}{c}{[\alpha]_{\mathrm{D}}{ }^{\mathrm{d}}} \\
(\mathrm{deg})\end{array}$ & $\begin{array}{c}{[\alpha]_{365}{ }^{\mathrm{d}}} \\
(\mathrm{deg})\end{array}$ \\
\hline 1 & 60 & $50 / 50(\mathrm{py} / \mathrm{ch})$ & $\mathbf{6}(0.010)$ & 28 & 8.1 & 2.17 & - & - \\
2 & 60 & $50 / 50(\mathrm{py} / \mathrm{ch})$ & $\mathbf{6}(0.020)$ & 26 & 3.0 & 1.29 & - & - \\
3 & 60 & $50 / 50(\mathrm{py} / \mathrm{ch})$ & $\mathbf{6}(0.030)$ & 21 & 10.3 & 2.29 & - & - \\
4 & 60 & $15 / 85(\mathrm{py} / \mathrm{ch})$ & $\mathbf{7}(0.020)$ & $-{ }^{\mathrm{f}}$ & - & - & - & - \\
5 & 60 & $50 / 50(\mathrm{py} / \mathrm{tol})$ & $\mathbf{7}(0.014)$ & $-\mathrm{f}^{\mathrm{f}}$ & - & - & - & - \\
6 & 60 & $50 / 50(\mathrm{py} / \mathrm{ch})$ & $\mathbf{7}(0.007)$ & $-\mathrm{f}^{\mathrm{f}}$ & - & - & - & - \\
\hline
\end{tabular}

${ }^{\mathrm{a}}$ Initiator $=\mathrm{AIBN}(0.03 \mathrm{M})$, time $=24 \mathrm{~h},[\mathrm{M}]_{0}=0.5 \mathrm{~mol} / \mathrm{L} .{ }^{\mathrm{b}}$ Methanol-insoluble part. ${ }^{\mathrm{c}}$ Determined by SEC in THF (PMMA standard) at $40{ }^{\circ} \mathrm{C} .{ }^{\mathrm{d}}$ In $\mathrm{CHCl}_{3}$ at r.t. ${ }^{\mathrm{e}} \mathrm{py}=$ Pyridine, $\mathrm{ch}=$ Chloroform, tol $=$ Toluene. ${ }^{\mathrm{f}}$ Not polymerized.

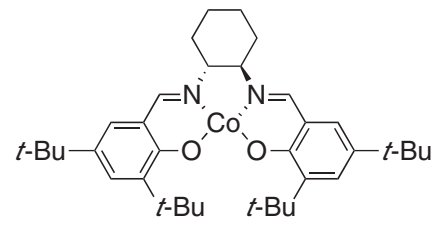

6

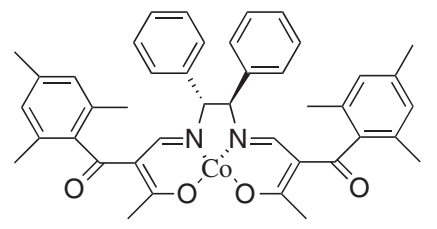

7 
were lower than those of one-handed helical poly(TrMA). This indicates that the one-handedness of the PBuTrMAMs may not be high. As the BuTrMAM is much stronger toward hydrolysis, the obtained polymer must be more stable when used as a chiral stationary phase for HPLC with polar alcoholic solvents. This stability would be very valuable, if one could prepare the polymer with a high chiral recognition.

Acknowledgment. This study was supported by Grant-in-Aid for Scientific Research (C) No. 17550116 by the Ministry of Education, Culture, Sports, Science, and Technology, Japan.

\section{REFERENCES}

1. Y. Okamoto and T. Nakano, Chem. Rev., 94, 349 (1994).

2. Y. Okamoto and E. Yashima, Prog. Polym. Sci., 15, 263 (1990)

3. E. Yashima, K. Maeda, and Y. Okamoto, Nature, 399, 449 (1999).

4. Y. Okamoto, T. Nakano, S. Habaue, K. Shiohara, and K. Maeda, J. Macromol. Sci., Part A: Pure Appl. Chem., 34, 1771 (1997).

5. G. Wulff, Angew. Chem., Int. Ed., 28, 21 (1989).

6. G. Wulff, Chemtech., 21, 364 (1991).

7. P. Pino, Adv. Polym. Sci., 4, 236 (1967).

8. Y. Okamoto, K. Suzuki, K. Ohta, K. Hatada, and H. Yuki, J. Am. Chem. Soc., 101, 4763 (1979).

9. Y. Isobe, D. Fujioka, S. Habaue, and Y. Okamoto, J. Am. Chem. Soc., 123, 7180 (2001).

10. S. Habaue, Y. Isobe, and Y. Okamoto, Tetrahedron, 58, 8205 (2002).

11. Y. Isobe, Y. Suito, S. Habaue, and Y. Okamoto, J. Polym. Sci., Part A: Polym. Chem., 41, 1027 (2003).

12. a) B. Ray, Y. Isobe, S. Habaue, M. Kamigaito, and Y. Okamoto, Polym. J., 36, 728 (2004).

b) B. Ray, Y. Okamoto, M. Kamigaito, M. Sawamoto, K. Seno, S. Kanaoka, and S. Aoshima, Polym. J., 37, 234 (2005).

13. T. Nakano and Y. Okamoto, "Controlled radical polymerisation," ACS Symposium Series No. 685, American Chemical Soceity, Washington D.C., 1998, p. 451.
14. T. Nakano, Y. Shikisai, and Y. Okamoto, Polym. J., 28, 51 (1996).

15. N. Hoshikawa, Y. Hotta, and Y. Okamoto, J. Am. Chem. Soc., 125, 12380 (2003).

16. M. Canle, W. Clegg, I. Demirtas, M. R. J. Elsegood, and H. Maskill, J. Chem. Soc., Perkin Trans., 2, 85 (2000).

17. T. Nakano, Y. Satoh, and Y. Okamoto, Polym. J., 30, 635 (1998).

18. a) Y. Okamoto, M. Adachi, H. Shohi, and H. Yuki, Polym. J., 13, 175 (1981).

b) Y. Okamoto, H. Hayashida, and K. Hatada, Polym. J., 21, 543 (1989).

c) K. Shiohara, S. Habaue, and Y. Okamoto, Polym. J., 28, 682 (1996).

d) S. Habaue, K. Shiohara, T. Uno, and Y. Okamoto, Enantiomer, 1, 55 (1996).

e) K. Shiohara, S. Habaue, and Y. Okamoto, Polym. J., 30, 249 (1998).

f) T. Uno, K. Shiohara, S. Habaue, and Y. Okamoto, Polym. J., 30, 352 (1998).

g) Y. Amano and Y. Okamoto, Polym. J., 37, 629 (2005).

19. K. Hatada, T. Kitayama, and K. Ute, Polym. Bull., 9, 241 (1983).

20. F. Toda, H. Miyamoto, S. Kikuchi, F. Nagami, and R. Kuroda, J. Am. Chem. Soc., 118, 11315 (1996).

21. Y. Okamoto, E. Yashima, M. Ihikura, and K. Hatada, Polym. J., 19, 1183 (1987).

22. Y. Okamoto, K. Suzuki, and H. Yuki, J. Polym. Sci., Polym. Chem. Ed., 18, 3043 (1980).

23. H. Kageyama, Y. Hayashi, S. Harada, Y. Kai, N. Kasai, Y. Okamoto, and K. Harada, Makromol. Chem., 186, 203 (1985).

24. A. K. M. F. Azam and Y. Okamoto, unpublished data.

25. a) T. Nakano and Y. Okamoto, Macromolecules, 32, 2391 (1999).

b) T. Nakano, K. Tsunematsu, and Y. Okamoto, Chem. Lett., 31, 42 (2002).

26. T. Nakano, M. Mori, and Y. Okamoto, Macromolecules, 26, 867 (1993).

27. a) H. Yuki, Y. Okamoto, and I. Okamoto, J. Am. Chem. Soc., 102, 6356 (1980).

b) Y. Okamoto, S. Honda, I. Okamoto, H. Yuki, S. Murata, R. Noyori, and H. Takaya, J. Am. Chem. Soc., 103, 6971 (1981). 